This is a self-archived version of an original article. This version may differ from the original in pagination and typographic details.

Author(s): Mathew Puthenparambil, Jiby

Title: Outsourcing within the Nordic context : Care services for older people in Finland

Year: 2018

Version: Accepted version (Final draft)

Copyright: (c) 2018 Taylor \& Francis

Rights: In Copyright

Rights url: http://rightsstatements.org/page/lnC/1.0/?language=en

Please cite the original version:

Mathew Puthenparambil, J. (2018). Outsourcing within the Nordic context : Care services for older people in Finland. Journal of Aging and Social Policy, 30(5), 440-457.

https://doi.org/10.1080/08959420.2018.1465800 


\section{Outsourcing within the Nordic context: Care services for older people in Finland}

\section{Jiby Mathew Puthenparambil}

To cite this article: Jiby Mathew Puthenparambil (2018): Outsourcing within the Nordic context: Care services for older people in Finland, Journal of Aging \& Social Policy, DOI: 10.1080/08959420.2018.1465800

To link to this article: https://doi.org/10.1080/08959420.2018.1465800

Accepted author version posted online: 16 Apr 2018.

Submit your article to this journal $\sqsubset$

LII Article views: 3

Q View related articles $\circlearrowright$

View Crossmark data \lceil 


\title{
Outsourcing within the Nordic context: Care services for older people in Finland
}

\author{
Jiby Mathew Puthenparambil \\ Postgraduate student \\ Social and Public Policy \\ University of Jyvaskyla \\ Department of Social Sciences and Philosophy \\ P.O. Box 35, FI-40014 \\ University of Jyvaskyla, Finland \\ Phone: +358449985641 \\ jimathew@jyu.fi
}

\section{Acknowledgements}

This work was supported by the "Linked Ageing: Interdependencies in Housing and Care in the Course of Later Life (LinkAge)" and the "Centre of Excellence in Research on Ageing and Care (CoE AgeCare)" research projects funded by Academy of Finland. Author is grateful to Teppo Kröger, University of Jyväskylä, Virpi Timonen, Trinity College, Dublin and Marta Szebehely, Stockholm University for their valuable comments on the manuscript, and also to Tomi Oinas, University of Jyväskylä for his statistical advice. The author is thankful to all the three reviewers for their thoughtful and constructive comments. Author also expresses gratitude to the Finnish Statistic and Indicator Bank (SOTKA-net) and Statistics Finland (Tilastokeskus) for making the national data available for research purpose.

\section{Outsourcing within the Nordic context: Care services for older people in Finland}

The early 1990s economic setback brought significant reforms favoring the outsourcing of care in Finnish municipalities. Here, outsourcing refers to the practice of municipalities employing private organizations through different means (e.g., open tendering) to deliver public care services. In this context, this study examines the growth in the outsourcing of service housing and home-help services in 311 municipalities from 2001 to 2015 and 
investigates the municipal factors associated with outsourcing using four dimensions: care needs, population size, economic situation, and political ideology of the municipality. The findings reveal a steep increase in the outsourcing of home-help and service housing. Care needs of older people is the most influential factor for outsourcing, particularly for service housing. Overall, the findings show a growing trend in private care provision in Finnish municipalities.

Keywords: Social care, outsourcing, older people, Finland, municipality.

\section{Introduction}

As in other Nordic countries, municipalities in Finland have an overall responsibility not only to organize health and social care provision for their residents but also to generate the major share of funding to support these services (Häkkinen, 2005). However, in contrast to the Nordic tradition of public provision, Finland has witnessed an accelerating growth trend in the outsourcing of care to private providers, especially for social service care for older people. Currently, the private sector is estimated to produce almost one-quarter of all health and social care services (Ministry of Social Affairs and Health, n.d). Among the

Nordic countries, Finland has been an eager promoter of this care market, although Sweden has also been more affected by marketization than Norway and Denmark (Meagher \& Szebehely, 2013).

During the economic recession of the early 1990s, overall municipal expenditures were downsized, especially care provision for older people that was once heavily subsidized by central grants (Kröger, 2011). During this period, a liberalist market ideology was promoted with an emphasis on how to increase the economy, efficiency and effectiveness of the social service delivery system (Anttonen \& Häikiö, 2011). Since that time, marketization ideas have become a dominating trend. Marketization refers to a process where market 
rationalities and practices are introduced into the public care sector (Meagher \& Szebehely, 2013). Outsourcing is a marketization instrument that is used to implement market-like mechanisms (Karsio \& Anttonen, 2013) and is generally referred to as a process by which public agencies allocate their responsibilities for delivering care services to private organizations while retaining control over the financing, commissioning, regulation and monitoring of those services (Stolt \& Winblad, 2009; Tynkkynen, 2013). The same definition applies in the Finnish context; however, in this study, outsourcing refers to the practice of municipalities employing for-profit or non-profit private organizations through different means (e.g., open tendering, service vouchers) to deliver public care services. In Finland, municipalities decide whether to outsource care services, whereas the regional state administrative agencies (AVIs) direct, license and oversee these private providers. The central government (Ministry of Social Affairs and Health) defines the legislation and policy frameworks.

The opening of the care market was indirectly present in the Social Welfare Act 710/1982, which entitled municipalities to organize and produce their own social care services and gave them liberty to purchase services from other municipalities and from external providers using central government grants (Karsio \& Anttonen, 2013). However, active promotion of such outsourcing by inducting for-profit organizations into care arrangement strengthened in the late 1990s and then accelerated from 2000 onwards. Other policies, such as the introduction of tax credits for domestic help in 2001 (which enabled a tax deduction for the purchase of private services), the voucher system introduced in 2004 (which included flat rate vouchers used to purchase private services with an option to top up from a user's own pocket), and the Public Procurement Act of 1992/2007 (which promoted fair competition between external providers) further expanded the scope of the care market in Finland (Anttonen \& Häikiö, 2011; Kröger \& Leinonen, 2012). Although Finnish 
municipalities have a long tradition of outsourcing the care of older people to non-profit organizations for both service housing and institutional care, the active role of for-profit providers became stronger only in the late 1990s (Karsio \& Anttonen, 2013).

In Finland, municipalities are not obliged by law or any other policy guidance to outsource their services; therefore, the degree of outsourcing and the methods used for outsourcing followed by different municipalities can be diverse and complex (see, Karsio \& Anttonen, 2013). However, limited knowledge is available regarding the actual outsourcing of public care services for older people in Finnish municipalities. In this context, this study focuses mainly on home-help services and service housing with 24-hour assistance, because these two services are considered important aspects of older people's long-term care, especially from an 'aging in place' perspective. Additionally, these two services are the most outsourced forms of social care for older people. Home-help refers to services related to personal care and the activities of daily life performed in the users' homes. These services may include activities such as bathing, dressing, toileting and sometimes home nursing (e.g., medical tasks, such as dressing wounds and performing medical tests). Service housing refers to housing that includes accommodation and related services (e.g., personal care). Ordinary rental flats and housing without daily or regular home-help services are excluded from this particular housing group. The difference between service housing and traditional institutional care is that service housing is always based on a rental relationship or owner-occupancy, where users pay separately for the services they use. The definitions of both services described above are derived from the Finnish Statistic and Indicator Bank (SOTKA-net, n.d). These two services have a clear distinction in their organization, and thus business opportunities differ. Home-help services are often provided by local companies with a small number of employees (often one) (Karsio \& Anttonen, 2013), and these services are easier to organize without any substantial investment except manpower. Conversely, service housing 
is mostly organized by larger firms due to the involvement of property ownership, which comprises a large investment. Larger companies are also involved in home-help services but are generally clustered in larger cities.

\section{Municipal factors and the outsourcing of care}

Several studies have examined the factors associated with the outsourcing of public services, but their results vary and demonstrate both similarities and dissimilarities. Generally, the outsourcing of care is considered a local governmental strategy used to regulate economic pressure on the government, expand service coverage, increase consumer choices and reduce administrative burdens (Green-Pedersen, 2002; Karsio \& Anttonen, 2013; Stolt \& Winblad, 2009; Rostgaard, 2011). In the literature, Boyne's (1998) work was notable; he examined the outsourcing of services across local governments in the United States using four broad dimensions of municipal factors (financial pressure, market structure, power of public employees and public preferences of local governments). Several studies conducted after Boyne's (1998) work have used these dimensions and others (e.g., administrative professionals, political orientation and policy diffusion) to broaden knowledge of the outsourcing process in local governments (Bel \& Fageda 2017; Bhatti, Olsen, \& Pedersen, 2009; Green-Pedersen, 2002; Pallesen, 2004; Petersen, Houlberg \& Christensen, 2015; Stolt \& Winblad, 2009). However, few studies have focused on the outsourcing of care services for older people (Petersen, Houlberg \& Christensen, 2015; Stolt \& Winblad, 2009), and even in these studies, the care needs of older people are missing as a factor that should be considered as a reason to outsource. Therefore, to understand the outsourcing of care services in Finnish municipalities, this study analyzed the care needs of older people as one dimension of municipal factors together with three other dimensions (population size, economic situation and political ideology). 
Care needs of older people. Few studies have used the 'care needs' dimension connected to a hypothesis that a higher number of older people in a population is associated with an increased likelihood of outsourcing (Stolt \& Winblad, 2009; Petersen, Houlberg \& Christensen, 2015). The theoretical argument behind this hypothesis is based on the notion that a larger older population will more likely increase the demand for long-term care needs (Stolt \& Winblad, 2009), which in turn puts pressure on the local government to maintain sufficient care support. As a consequence, a local government may be likely to outsource services to external providers to regulate the increasing care demands (Meagher \& Cortis, 2009; Rostgaard, 2011). A single measurement, such as the quantity of the older population, does not fully represent the care needs of older people. A more precise measurement, such as limitations in activities of daily living (e.g., eating and toileting) of older people, is preferable as a measure of need; however, due to the absence of such measurements in the available data, this study includes five proxy indicators to reflect care needs. Pensioner's care allowance is a tax-free benefit paid to older people who need support in daily functions to supplement extra costs due to illness or disability. It is only provided to a person whose ability to look after him- or herself remains impaired for one year and who needs care on a daily basis. Pensioner's care allowance is used here as a measurement based on an assumption that an increase in the number of people receiving pensioner's care allowances is most likely associated with an increased care demand. Another proxy indicator used here is the proportion of older people living alone. Several studies have reported that older individuals living alone are more likely to require care from formal or informal sources due to the lack of spousal support and growing health issues (Hammar, Rissanen \& Perälä 2008). Presently, 47.2\% of people aged 75 years and above in Finland live alone (SOTKA-net, n.d). An increasing percentage of people living alone most likely reflects the possibility of increasing care demands. The other two proxy variables included in the analysis to represent 
the increasing demand for care in municipalities are the number of people receiving regular home-help (people with a valid care plan or receiving home care at least once per week) and people living in residential care (including people living in institutional care or service housing). Therefore, the hypothesis herein is that municipalities with higher care needs for older people are more likely to contract out their social care services.

Population size. The population size of the municipality is recurrently included as an explanatory variable based on the theoretical argument that the availability of external providers is higher in larger municipalities due to their better market opportunities and because competition between providers is likely to reduce the service cost, which in turn encourages municipalities to outsource more services (Hefetz \& Warner, 2011; Petersen, Houlberg, \& Christensen, 2015). These arguments are more logical in terms of the outsourcing of care; for example, in home-help services, private providers are more likely to focus their businesses in densely populated municipalities because shorter distances between users create a better market than long distances in sparsely populated municipalities (Stolt \& Winblad 2009). Although population size is a debatable measurement (Boyne, 1998; Petersen, Houlberg, \& Christensen, 2015), it is still used to assess the market capacity in the absence of other valid variables. The hypothesis herein is that populous municipalities are more likely to outsource care services to private providers than smaller municipalities.

Economic situation. In the literature, the economic condition of the municipality is considered an important explanatory factor. The main argument is that municipalities experiencing fiscal stress are more likely to outsource their services (Bel \& Fageda, 2017; Zullo, 2009; Geys \& Sørensen, 2016), because outsourcing help municipalities to save costs without increasing the municipal tax, reducing the service coverage or eliminating care provisions. The counterargument is that affluent municipalities are likely to 'experiment' with innovation by accommodating private providers, since they have adequate resources (in 
terms of finance and administration) to organize the complexity of outsourcing in an efficient manner (Bhatti, Olsen, \& Pedersen, 2009; Pallesen, 2004). In a recent study conducted in Norway, Geys \& Sørensen (2016) found that decreased municipality revenues positively correlated with outsourcing in the public sector. Other researchers have included different indicators, such as the ratio of local taxes to local income, local tax level, total expenses and total debt of the municipality, to capture a picture of the actual fiscal influence on outsourcing (Boyne, 1998; Petersen, Houlberg, \& Christensen, 2015; Stolt \& Winblad, 2009; Warner \& Hebdon, 2001). The annual contribution margin, which indicates the adequacy of the income situation in the municipalities by measuring the difference between the revenues (e.g., taxes) and the running costs of the municipality, was also used as an indicator (Fredriksson, Hyvärinen, Mattila, \& Wass, 2010). However, the findings of these studies show mixed results (i.e., a negative relationship, a positive relationship, or no relationship). Therefore, to reanalyze the situation and to understand the relationship between economic factors and the outsourcing process in Finnish municipalities, this study uses four variables to represent the economic situation. First, the tax revenue (collected from taxes on income, profits and other taxes) reflects the economic sufficiency of the municipality (Geys \& Sørensen, 2016). A higher tax revenue indicates a stronger economic condition of the municipality. The second indicator is health and social care expenditures; this indicator echoes the care-related fiscal stress on the municipality. The other two variables are central government grants and the annual contribution margin. Central government grants are seen as a significant factor that causes financial constraints for municipalities (Yliaska 2010, Hoppania 2015). From the late 1990s onward, central grants for municipalities were significantly downsized, which affected the overall revenues of the municipalities. However, these grants still aim to equalize the financial conditions of municipalities by supporting those in a weaker economic condition in particular to guarantee the availability of public services in all parts of the country. Thus, the 
amount of central grants can be used as an indicator of the economic strength of each municipality. The annual contribution margin indicator measures the difference between revenues and the running costs of the municipality; a negative value indicates that the revenues are insufficient to cover all operational costs.

Political ideology. Previous studies have noted that countries with right-wing governments introduce various market-oriented reforms in the public sector, whereas leftwing parties stand for more public provisions (Green-Pedersen, 2002; Plantinga, de Ridder \& Corra, 2011; Sundell \& Lapuente, 2012). This scenario was also true in Finland to some extent during the recession in the 1990s, when the then-right-wing central government implemented many market-type reforms in the public sector. Fredriksson, Hyvärinen, Mattila and Wass (2010) noted that the significance of political ideology on policy changes in Finland was very complex; for example, local politicians who are themselves local government employees show less political affiliation (in terms of right-wing or left-wing ideology) than their colleagues who are not hired by these municipalities. Therefore, the trends and practices of outsourcing can also be shaped by the whole institutional structure and the rationality of governance (Yliaska, 2014). A cross-national study from England, Australia, New Zealand, Norway, and Sweden (Zehavi, 2012) and another study (Stolt \& Winblad, 2009) from Sweden supported the existence of a strong relationship between rightwing parties and market reforms. However, a study conducted in Finland revealed no significant relationship between right-wing parties and market liberalization in the public sector (Fredriksson, Hyvärinen, Mattila, \& Wass, 2010). Nevertheless, recent political debates on strengthening the role of external providers in care services in Finland has led to the inclusion of right-wing parties as an explanatory variable in our analysis to enable comparisons with findings from previous studies. Therefore, the hypothesis herein is that 
municipalities led by a right-wing majority government are more likely to outsource their social care services than municipalities led by a right-wing minority government.

\section{Research Question}

This study aims to understand the general trends in the growth of the outsourcing of home-help services and service housing with 24-hour assistance services in Finnish municipalities. More precisely, the research questions of the study ask how much growth has occurred in the number of municipalities involved in outsourcing and whether changes have occurred in the quantity and intensity of outsourcing. In additional, this study investigates whether and how municipal factors (care needs of older people, population size, economic situation and political ideology) are associated with the outsourcing of these two key care services.

\section{Methodology}

\section{Sample and Data Sources}

The quantitative data for this study were obtained from the Finnish Statistic and Indicator Bank (SOTKA-net) and Statistics Finland (Tilastokeskus). These statistical banks offer key population data for all Finnish municipalities starting in 1990. The study includes all 311 municipalities (as recorded in 2015) in Finland from 2001 to 2015. The political party variable was collected from Statistics Finland, whereas the other variables were retrieved from the Finnish Statistic and Indicator Bank (SOTKA-net). Data from these banks are considered both valid and reliable; indeed, several studies have used these databanks (Anttonen \& Haïkïö, 2011; Kröger \& Leinonen, 2012). Ethical issues do not apply in this study, because the data are freely available for research purposes from the above databanks.

\section{Measurement}

Dependent and independent variables. Home-help services and service housing for 24-hour assistance were measured as dichotomous variables. The home-help variable was 
coded as "1" if the municipality purchased services from private providers (including both for-profit and non-profit providers) and "0" for municipalities not involved in outsourcing; the same procedure was applied to service housing. For the independent variables, all variables concerning the care needs of older people theme were measured in percentages except for the pensioner's care allowance, which was reported as the number of recipients per 1000 inhabitants. Additionally, all variables in the above theme belonged to the age group 65 years and above except the people living alone variable, which represented the age group of 75 years and above. The population size of the municipality was converted into a natural log scale to reduce skewness in the data. All economic situation variables were measured in euros per capita; however, to overcome the skewness in the data, these variables were reduced into smaller units (measured in 100s of euros). The total percentages of municipal council members from five political parties (National Coalition Party (KOK), Christian Democrats in Finland (KD), Swedish People's Party in Finland (RKP), Centre Party of Finland (KESK) and the Finns Party (PS)) were counted in the 'right-wing parties' variable.

\section{Data Analysis}

This study used a simple graphical analysis (i.e., line diagrams and scatters plots) for its descriptive analyses and a generalized estimating equations (GEE) model to analyze the association between municipal factors and outsourcing using panel data. The GEE was considered a suitable technique to analyze the data due to the dependent variables, which were measured repeatedly (at 2-year intervals) within the same municipalities for a period of 15 years (2001 to 2015). The "GEE model is a population-average estimation which measurement is nested within individuals and its explanatory variables indicating the expected changes in the population for a unit change in one of the predictor variables" (Heck, Thomas, \& Tabata, 2013, p. 198). An advantage of GEE models is that they allow different correlation structures to be assumed within units in the model. Measurements of longitudinal 
data are usually highly correlated when they are close in time and uncorrelated when the measurements are more distant. To confirm this assumption and to select a suitable correlation matrix, within-subject correlation structures for dependent variables were generated prior to the GEE analysis. The result showed a steep decrease in correlation coefficients whenever the time interval between measurements increased, which led to the conclusion that an autoregressive correlation [AR(1)] matrix was an appropriate model (Heck, Thomas, \& Tabata, 2013). However, robust estimates for the standard error were included to maintain a constant inference and to rectify any issue resulting from the selection of an incorrect working correlation structure. The GEE model is not limited to explaining differences between subjects but also examines changes over time within subjects. The data were analyzed using IBM SPSS version 22. The results were presented using beta coefficients with standard errors and 95\% confidence intervals. A multiple imputation method was used to overcome the problem of missing data in the service housing variable. However, the outcome from the original data and the imputed data showed very similar results with very slight/ignorable changes in the regression coefficient.

\section{Results}

Figure 1 describes the increase in the number of municipalities outsourcing homehelp services and service housing with 24-hour assistance between 2001 and 2015. In 2001, 113 municipalities (out of 311) outsourced at least some of their service housing to the private sector; however, in 2015 , the count reached 191, indicating a growth of $69 \%$ over a 15-year period. The number of municipalities outsourcing home-help services remained nearly stable for the whole period except in 2015, when a fluctuation occurred. In 2015,89 municipalities were using private home-help support.

\section{[Please insert Figure 1 here]}


Figure 2(a) shows the overall provision of home-help visits by both public entities and private providers. In 2015, 89 Finnish municipalities (out of 311) purchased approximately two million home-help visits from the private sector with an average annual growth rate of $14.5 \%$. However, the growth of home-help visits over the last four years was enormous. A similar trend was observed in service housing in Figure 2(b); the number of people living in service housing rose from 6,000 in 2001 to 19,000 in 2015 . The number of people receiving service vouchers for home-help also doubled (although the growth was slower), and public service housing also increased. Notably, users of traditional institutional homes provided by both public and private providers decreased considerably over the last 15 year period (not reported in the results).

\section{[Please insert Figure 2 here]}

Figure 3 presents the population-based analyses to visualize the distribution of outsourcing in the different municipalities $(68 \%$ of Finnish municipalities have less than 10,000 people). The proportion of private home-help visits was determined by dividing the total number of home-help visits outsourced to private providers by the total number of home-help visits provided by the municipality (including both outsourced services and inhouse services). Although several municipalities outsourced part of their services, few municipalities outsourced more than $25 \%$ of their total home-help visits. Interestingly, several municipalities outsourced all of their home-help services (see Figure 3(a)). However, outsourcing of service housing was significant in both highly populated and smaller municipalities.

\section{[Please insert Figure 3 here]}

The associations between the municipal level factors and the outsourcing of public home-help services and service housing for older people are presented in Table 1 for two models: a crude model (unadjusted) and a full model (adjusted for all variables). The time 
variable in service housing in both models showed a significant positive association, thereby indicating a growing trend toward involving private providers over the time period. All the variables in the crude model except the share of older people, central government grants, annual contribution margin and right-wing parties showed a significant association with the use of private service housing. However, after adjustment for all of the variables, only the care need factors (except the share of older people and people receiving regular home-care) and the population size $(\beta=2.40, p<.001)$ revealed a significant association.

\section{[Please insert Table 1 here]}

In the crude home-help services model, the independent variables showed a mixed pattern of positive and negative associations. After adjusting for all of the variables, year variable, recipients of a pensioner's care allowance $(\beta=0.02, p<.01)$, population size $(\beta=0.73, p<.001)$ and health and social care expenditures $(\beta=0.06, p<.05)$ showed positive associations. As expected, right-wing parties (in home-help and service housing) did not display any significant result $(p>.05)$. Therefore, the hypothesis regarding the connection between right-wing parties and outsourcing was not supported by this study.

\section{Discussion}

This study sought to understand the ongoing trends in the outsourcing of public home-help and service housing with 24-hour assistance services in Finnish municipalities. The results show an expected growth trend in private care services for older people. For the past decade, privately provided services have increased continuously in Finland, mainly for service housing (see Figure 1). Each year, an average of 7 additional municipalities were engaged in outsourcing their service housing. Although only a limited number of municipalities actively outsourced their home-help services, the share of services purchased from this sector increased considerably. The number of people using service vouchers for home-help also doubled over the past decade. As mentioned in the introduction, service 
housing and home-help services are organized differently; therefore, their patterns of growth differ. However, this study cannot provide a clear answer regarding which service has an upper hand in the care market or how the business opportunities in these services have influenced growth because the data from the study provide limited information on this topic. Therefore, this study can only confirm that both services are increasingly produced by private organizations. The overall trends show a clear pattern of an increasing market approach for care for older people. Like Anttonen and Haïkiö (2011), this study also concluded that Finland is rapidly moving toward mixed welfare production and away from the historical tradition of state-centered welfare production.

The number of municipalities involving private providers and the number of people using private service housing (see Figure 2(b)) have increased significantly over the last 15 years. A glance at the history of service housing helps elucidate this trend. Private service housing traditionally was delivered in Finland mainly by non-profit organizations. However, the implementation of procurement legislation (Public Procurement Act 1505/1992, followed by the Act on Public Contracts 348/2007 based on the EU directive) urged municipalities to promote fair competition in their outsourcing procedures. Even non-profit organizations have to resemble themselves into profit-making organizations to participate in the tendering practices (based on competition neutrality) of the municipalities (Karsio \& Anttonen, 2013). This factor is not the only reason for the transformation of non-profit organizations, because the implementation of Lotteries Act 2001 (pushing Finland's Slot Machine Association-a non-profit gambling company-to discontinue its financial support of service housing provisions to non-profit organizations) and changes in national and local reforms have also been involved (Karsio \& Anttonen, 2013). The policy goal behind the implementation of service housing is to minimize traditional public institutional care by promoting a homebased care model (Anttonen \& Karsio, 2016); additionally, a strong market-oriented approach 
underlies this transition (Karsio \& Anttonen, 2013). Officially, people living in service housing are considered to be living in their own homes, and these residents pay separately for all services they use. This type of care arrangement helps municipalities save care expenses by shifting costs to the users themselves (Hoppania, 2015) and to the publicly funded social insurance system (e.g., to cover the cost of medicines). Finnish municipalities have often found service housing to be a cheaper option than traditional institutional care, because its users pay significantly higher fees (Hoppania, 2015). This fact may explain why the numbers of people living in traditional institutional homes provided by both public and private providers have decreased considerably over the last 15 years (not reported in the results). Almost all social care services in Finland are subject to a moderate fee, which is relatively higher than the fees in other Nordic countries (Karsio \& Anttonen, 2013). However, no comparable data are available to analyze the impact of user fees, since each municipality has its own user fee policy. Furthermore, no separate data are available to differentiate non-profit from for-profit organizations in this respect, and therefore, the findings should be interpreted with caution.

In terms of the research question on the municipal factors and their associations with the outsourcing of home-help and service housing, the results show similar patterns between these two services. The care need factors examined herein, such as recipients of pensioner's care allowances, people living alone and people living in residential care, were positively associated with the outsourcing of service housing. This finding is in line with the claim that increasing care needs are more likely to create pressure on local governments to purchase care from external providers in order to maintain proper service coverage (Meagher \& Cortis, 2009). Increasing demand for care in a municipality can become a flourishing market for private providers. This situation results in a stronger mixed care model than the traditional state-centered care model, in which public agencies are solely responsible for producing and 
providing services. Unsurprisingly, a positive association exists between populous municipalities and the outsourcing of care. Larger municipalities most likely find outsourced services much cheaper due to competition between providers (Hefetz \& Warner, 2011; Petersen, Houlberg \& Christensen, 2015). Moreover, and this point is especially relent with respect to service housing, they do not need to invest in building their own infrastructures.

This study is not completely in line with other studies that have recognized the economic pressure on the municipality as a strong indicator of greater outsourcing (Bel \& Fageda, 2017; Bhatti, Olsen, \& Pedersen, 2009). Only the health and social expenditure variable showed a positive relationship with the outsourcing of home-help services. Therefore, the overall "fiscal stress" assumption cannot be verified from this outcome, because other economic variables, especially the annual contribution margin, show nonsignificant results. Furthermore, the above outcome can be given weight only if the costsaving approach to reduce care-related fiscal stress is the core intention of the local government (Boyne, 1998; Green-Pedersen, 2002; Hefetz \& Warner, 2011). The local government's decision to outsource is often argued to not be based purely on fiscal stress or any one factor but instead is grounded on a broader capacity of the institutional structure (i.e., the financial capacity, administrative ability and rationality of governance), rising care demands and the influence of neighboring municipalities (Bhatti, Olsen, \& Pedersen, 2009; Stolt \& Winblad, 2009; Yliaska, 2014). Some researchers have even claimed that outsourcing is the 'politics of good times' (Bhatti, Olsen, \& Pedersen, 2009; Bel \& Fageda, 2017). Therefore, this study assumes that the positive outcome of the health and social expenditure variable may be because of increasing care demand in the municipality or the rationality of governance (Stolt \& Winblad, 2009; Yliaska, 2014). Overall, the findings of this study are rather mixed. The need factors are closely associated with the outsourcing of service housing, whereas the outsourcing of home-help services shows a combination effect of population 
size, pensioner's care allowance and health and social care expenditures. In line with previous studies (Fredriksson, Hyvärinen, Mattila, \& Wass, 2010), this study did not find any significant association between right-wing parties and the outsourcing of care for older people.

Another interesting outcome was that several of the Finnish municipalities (see Figure 3) outsourced all of their service housing and home-help services. There is no clear explanation why this shift has occurred. Tynkkynen (2013) reported that this move was a countermeasure against the aggregation of municipalities and was also due to unsuccessful cooperation between neighboring municipalities in organizing care services. The findings from this study support the care needs of older people as a main factor for outsourcing; the popularity of market-oriented ideology in municipal governance and/or the influence of neighboring municipalities (Stolt \& Winblad, 2009) may be other reasons. However, this assumption cannot be studied using a quantitative method and instead requires a qualitative approach.

The outsourcing of care services to the (for-profit) private sector is a more recent phenomenon in Finland than in many other post-industrial countries, but a rapidly growing trend can be observed at present. Currently, the traditional Finnish social care model (statecentered care production) as a whole is slowly transforming and moving into a new phase (a mixed model with a strong presence of for-profit production) due to the influence of marketization. A mixed care model may bring challenges to the care system. For example, a report from the Finnish trade union for the public and welfare sectors (JHL, n.d) confirmed that some municipalities were compromising quality measures by outsourcing their services to the lowest bidder. Therefore, the effects of this model need to be studied thoroughly in the future. The growth in private service housing and the absorption of small-scale enterprises by large national and international companies raises some concerns about the direction in which 
the service housing market is progressing (Karsio \& Anttonen, 2013). No empirical data or evidence are available concerning the implications of outsourcing in home care services in terms of costs and quality; this topic has been untouched and needs to be studied further. The overall trend shows that municipalities are keen to downscale care costs and transfer financial responsibilities to the service users themselves (Hoppania, 2015). Presently, a large-scale structural reform of social and health care (the so-called SOTE reform) has been initiated in Finland, but this reform will not be implemented until 2020. Through this reform, municipal responsibility for organizing care support will be transferred to a larger regional authority. This reform relies heavily on the "freedom of choice" concept and the promotion of greater participation by the private sector. Thus, the public care sector will likely rely heavily on private providers to produce care services in the near future while the public sector handles the roles of administrator, financier and regulator. Therefore, further research on this topic is needed to explicate the ongoing trend and its implications for the care of older people.

\section{Limitations}

Like all scientific research, this study had its weaknesses. The construction of the dependent variable could have influenced the results, because the municipalities were coded as using outsourcing even when only a few users (e.g., less than 10 users) received outsourced services. The outcome of the care needs variables should be observed with some caution, because these variables do not represent a precise measurement of care needs but instead serve as proxy indicators. Additionally, due to the decentralized service organization structure, different local authorities may use different need assessment thresholds while arranging services for older people, which may not be fully captured through these care need variables. These data do not contain separate information on non-profit and for-profit organizations, because the two organization types are merged in the statistical bank. This study also did not analyze the transaction/unit costs of private production due to the 
unavailability of accurate data. Despite these limitations, this study has several strengths. This study contributes to knowledge on the changing character of the Nordic welfare model. The results show a developing trend in the outsourcing of care in a Nordic welfare state and examine the relationship between municipal level factors and the outsourcing of care through a longitudinal approach, which is an uncommon focus in previous research.

\section{Conclusion}

In summary, the outsourcing of home-help and service housing for older people is increasing steadily in Finland. Although the outsourcing of home-help services is more common in highly populated municipalities, it is also spreading to more sparsely populated municipalities. However, the outsourcing of service housing is scattered across municipalities without any clear discernible pattern. The care needs of older people are the main influencing factor for outsourcing, particularly for service housing. The present economic austerity, coupled with the increasing demand for care for older people, raises intriguing and necessary questions about whether the current outsourcing of public services will remain the same, increase further or even expand rapidly in the future.

\section{References}

Anttonen, A., \& Karsio, O. (2016). Eldercare service redesign in Finland: deinstitutionalizeation of long-term care. Journal of Social Service Research, 42(2), 151-166.

Anttonen, A., \& Häikiö, L. (2011). Care 'going market': Finnish elderly-care policies in transition. Nordic Journal of Social Research, 2, 70-90.

Bel, G., \& Fageda, X. (2017). What have we learned from the last three decades of empirical studies on factors driving local privitisation? Local Government Studies, 43, 503511.

Bhatti, Y., Olsen, A. L., \& Pedersen, L. H. (2009). The effects of administrative professionals on contracting out. Governance, 22(1), 121-137. 
Boyne, G. A. (1998). The determinants of variations in local service contracting garbage in, garbage out? Urban Affairs Review, 34(1), 150-163.

Fredriksson, S., Hyvärinen, O., Mattila, M., \& Wass, H. (2010). The Politics of Competitive Tendering: Political Orientation and Attitudes towards Contracting Out among Finnish Local Politicians. Local Government Studies, 36(5), 637-654.

Geys, B., \& Sørensen, R. J. (2016). Revenue scarcity and government outsourcing: empirical evidence from Norwegian local governments. Public Administration, 94(3), 769-788.

Green-Pedersen, C. (2002). New Public Management Reforms of the Danish and Swedish Welfare States: The Role of Different Social Democratic Responses. Governance, $15(2), 271-294$.

Heck, R. H., Thomas, S., \& Tabata, L. (2013). Multilevel modeling of categorical outcomes using IBM SPSS. New York: Routledge Academic.

Hefetz, A., \& Warner, M. E. (2011). Contracting or public delivery? The importance of service, market, and management characteristics. Journal of Public Administration Research and Theory, 22(2), 289-317.

Häkkinen, U. (2005). The impact of changes in Finland's health care system. Health Economics, 14, 101-118.

JHL (n.d.). More and more Finnish municipalities taking back outsourced services. Retrieved August 16, 2015 from http://www.jhl.fi/portal/en/jhl_info/news/?bid=5082

Karsio, O., \& Anttonen, A. (2013). Marketisation of eldercare in Finland: Legal frames, outsourcing practices and the rapid growth of for-profit services. In G. Meagher, \& M. Szebehely (Eds.), Marketisation in Nordic eldercare: A research report on legislation, oversight, extent and consequences (pp 127-161). Stockholm: Stockholm University. 
Kröger, T. (2011). Retuning the Nordic welfare municipality: Central regulation of social care under change in Finland. International Journal of Sociology and Social Policy, 31(3/4), 148-159.

Kröger, T., \& Leinonen, A. (2012). Transformation by stealth: The retargeting of home care services in Finland. Health and Social Care in the Community, 20(3), 319-327.

Meagher, G., \& Cortis, N. (2009). The political economy of for-profit paid care: theory and evidence. In D. King \&c G. Meagher (ed.), Paid Care in Australia: Profits, Purpose, Practices (pp 13-42). Sydney: Sydney University Press.

Meagher, G., \& Szebehely, M. (2013).Marketisation in Nordic eldercare: a research report on legislation, oversight, extent and consequences. Stockholm: Stockholm University.

Ministry of Social Affairs and Health (n.d) Private social and health services. Retrieved July 01 2017, from http://stm.fi/en/private-health-care.

Pallesen, T. (2004). A political perspective on contracting out: The politics of good times. Experiences from Danish local governments. Governance, 17(4), 573-587.

Petersen, O. H., Houlberg, K., \& Christensen, L. R. (2015). Contracting out local services: A tale of technical and social services. Public Administration Review, 75(4), 560-570.

Plantinga, M., de Ridder, K., \& Corra, A. (2011). Choosing whether to buy or make: The contracting out of employment reintegration services by Dutch municipalities. Social Policy \& Administration, 45(3), 245-263.

Rostgaard, T. (2011). Care as you like it: the construction of a consumer approach in home care in Denmark. Nordic Journal of Social Research, 2, 54-69.

SOTKA-net. (n.d.). Statistical information on welfare and health in Finland. Retrieved June 22, 2017, https://www.sotkanet.fi/sotkanet/en/index

Stolt, R., \& Winblad, U. (2009). Mechanisms behind privatization: A case study of private growth in Swedish elderly care. Social Science and Medicine, 68(5), 903-911. 
Sundell, A., \& Lapuente, V. (2012). Adam Smith or Machiavelli? Political incentives for contracting out local public services. Public Choice, 153(3-4), 469-485.

Tynkkynen, L. (2013). Towards Partnership? Studies on public-private collaboration in health and elderly care services in Finland. (Doctoral dissertation). Tampere press. Retrieved July 16 2015, from http://urn.fi/URN:ISBN:978-951-44-9023-1

Warner, M., \& Hebdon, R. (2001). Local government restructuring: privatization and its alternatives. Journal of Policy Analysis and Management, 20(2), 315-336.

Yliaska, V. (2014). Tehokkuuden toiveuni: uuden julkisjohtamisen historia Suomessa 1970luvulta 1990-luvulle. (Doctoral dissertation). Helsinki: Helsinki University.

Hammar, T., Rissanen, P., \& Perälä, M. L. (2008). Home-care clients' need for help, and use and costs of services. European journal of ageing, 5(2), 147.

Hoppania, H. (2015) Care as a Site of Political Struggle. (Doctoral dissertation). Helsinki: Helsinki University. Retrieved July 16 2015, from http://urn.fi/URN:ISBN:978$951-51-1020-6$

Zehavi, A. (2012). Welfare state politics in privatization of delivery: Linking program constituencies to left and right. Comparative Political Studies, 45(2), 194-219.

Zullo, R. (2009). Does fiscal stress induce privatization? Correlates of private and intermunicipal contracting, 1992-2002. Governance, 22(3), 459-481. 


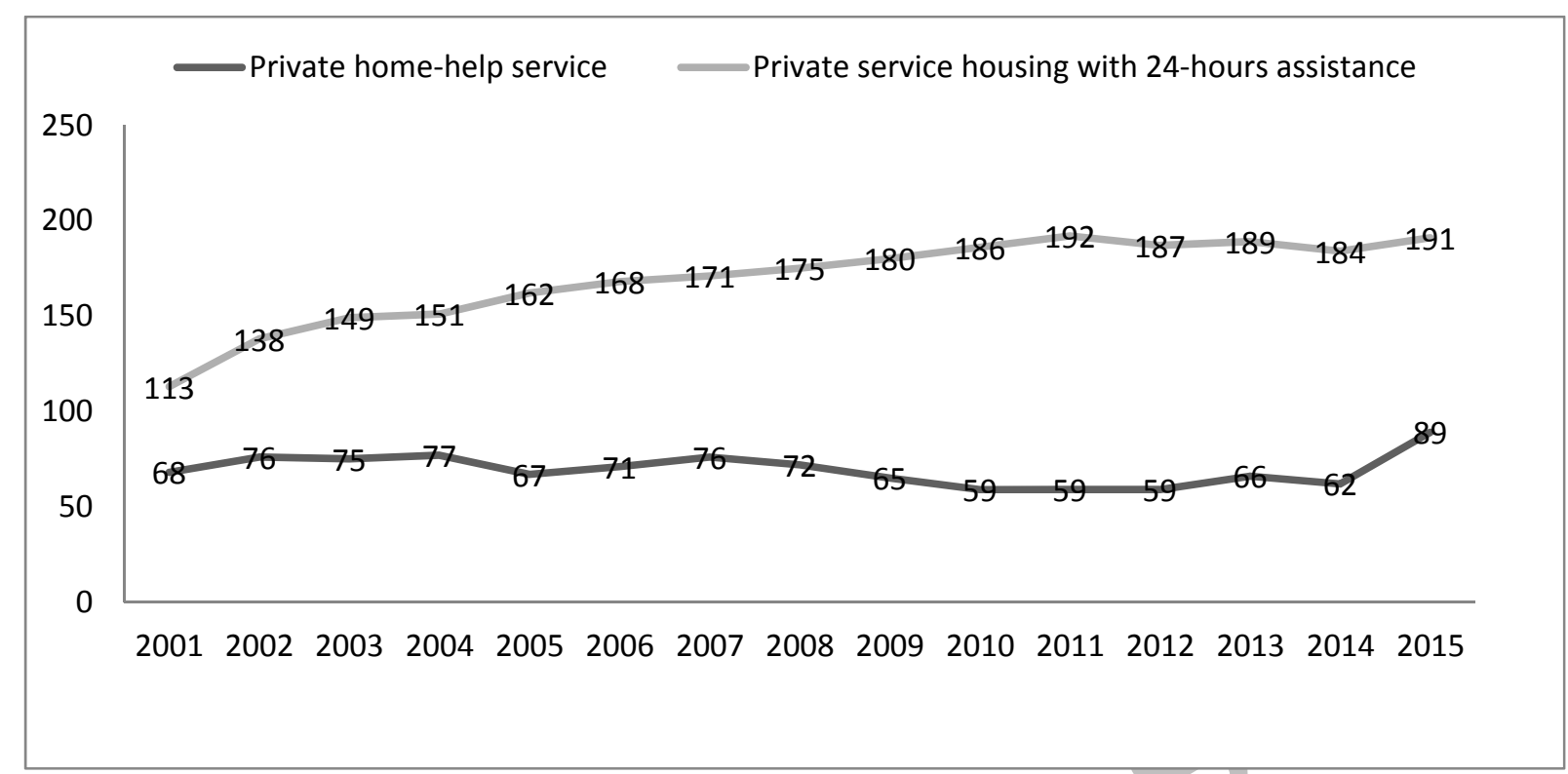

Figure 1. Number of municipalities outsourcing home-help services and service housing with 24-hour assistance (2001-2015) 


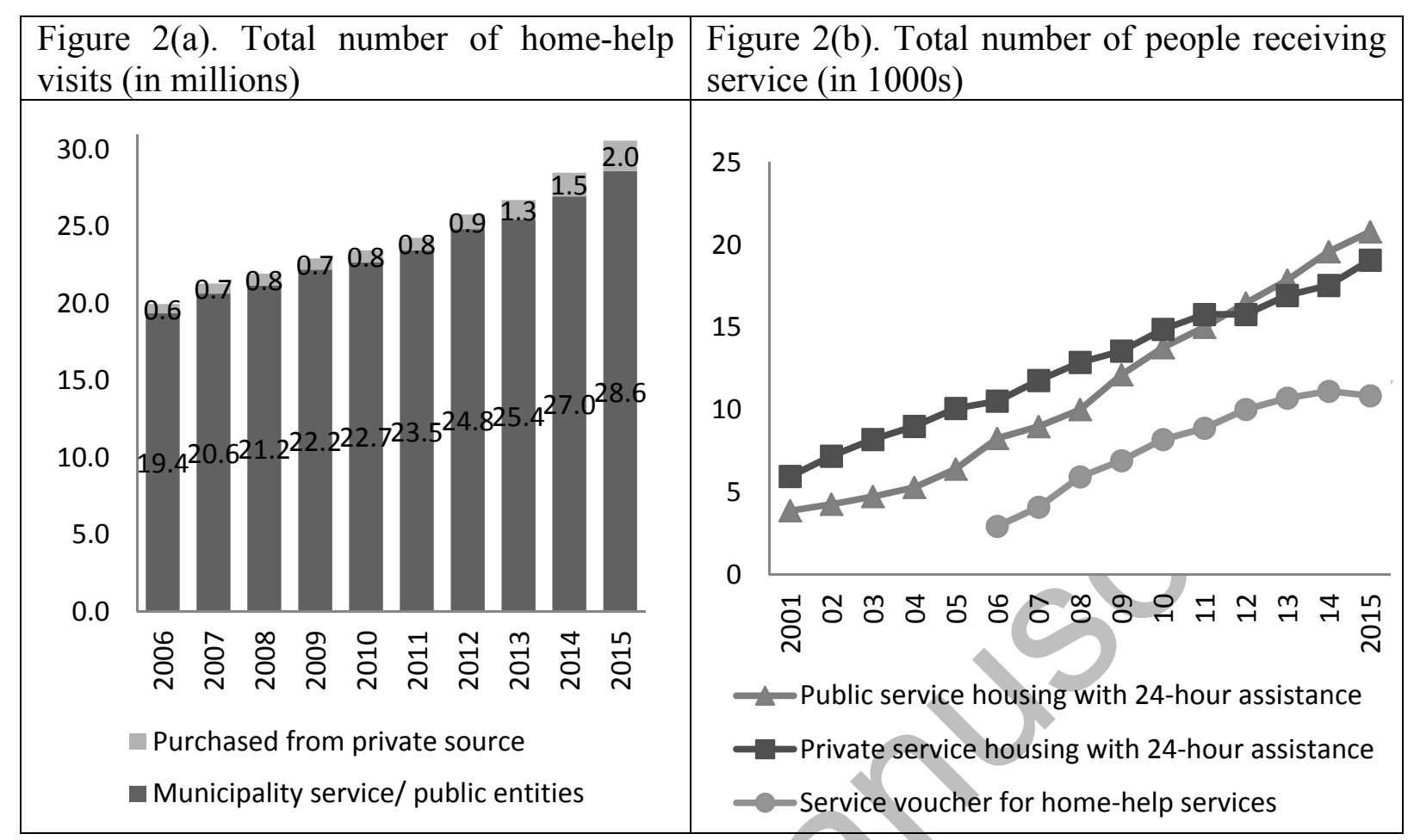

Figure 2. Total number of home-help visits and total number of people receiving service housing with 24-hour assistance and service voucher in Finland (2001-2015). 
Figure 3(a). Percentage of outsourced home-help visits

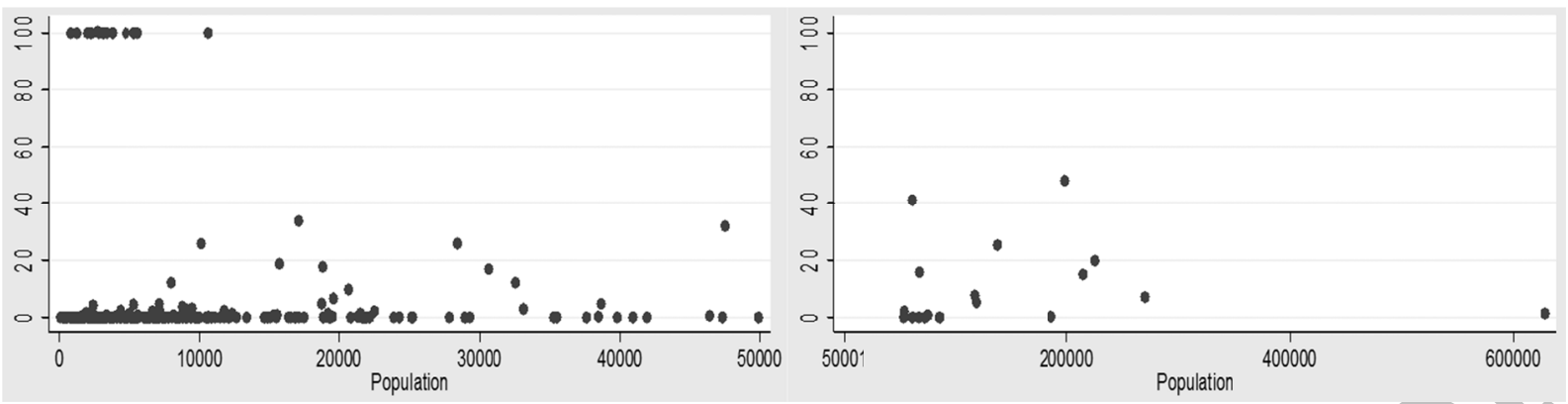

Figure 3(b). Percentage of people living in outsourced service housing with 24-hour assistance

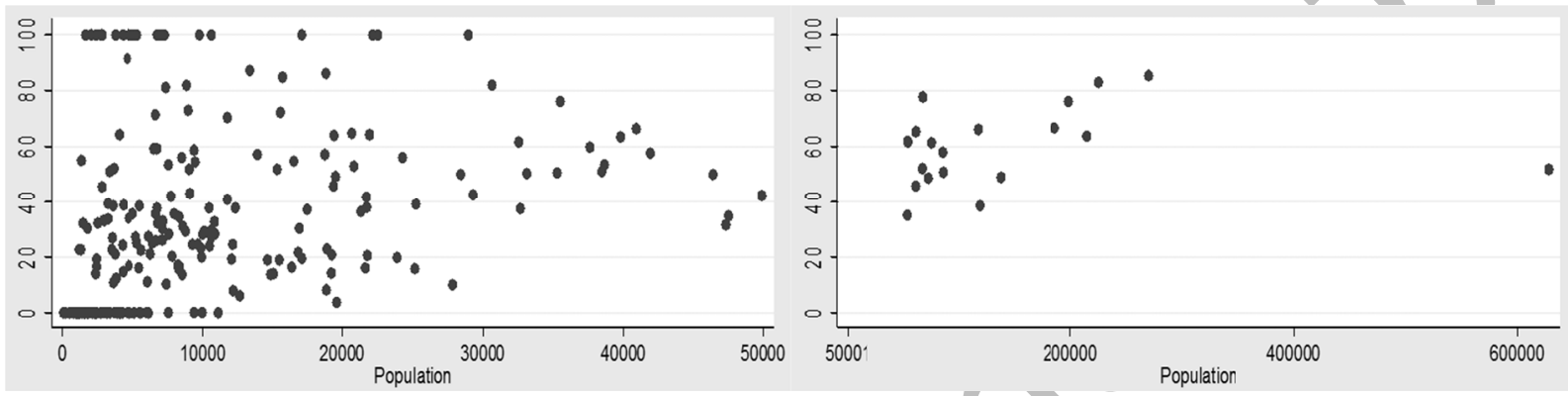

Figure 3. Proportion of outsourced home-help visits and service housing with 24-hour assistance in municipalities with different population size (in 2015) 
Table 1. Municipal factors associated with outsourcing of service housing with 24-hours assistance and home-help services

(Longitudinal data using generalized estimating equations for binary outcome, 2001-2015 (2year intervals), $\mathrm{N}=2488$.

\begin{tabular}{|c|c|c|c|c|c|}
\hline \multirow[t]{3}{*}{ Variables } & \multirow[t]{3}{*}{ Range } & \multicolumn{2}{|c|}{$\begin{array}{c}\text { Outsourced service housing with } \\
\text { 24-hours assistance } \dagger\end{array}$} & \multicolumn{2}{|c|}{$\begin{array}{c}\text { Outsourced home-help } \\
\text { services } \dagger\end{array}$} \\
\hline & & Crude Model & Full Model & Crude Model & Full Model \\
\hline & & $\beta(S E)$ & $\beta(S E)$ & $\beta(S E)$ & $\beta(S E)$ \\
\hline \multicolumn{6}{|l|}{ Year dummies (Ref: } \\
\hline 2015 & - & $1.15(0.14)^{* * *}$ & $2.04(0.54) * * *$ & $0.38(0.17)^{*}$ & $-0.30(0.49)$ \\
\hline 2013 & - & $1.00(0.13)^{* * *}$ & $1.85(0.49)^{* * *}$ & $-0.04(0.17)$ & $-0.96(0.45)^{*}$ \\
\hline 2011 & - & $1.21(0.14)^{* * *}$ & $1.91(0.46)^{* * *}$ & $-0.18(0.18)$ & $-0.97(0.38) *$ \\
\hline 2009 & - & $0.92(0.12)^{* * *}$ & $1.66(0.33)^{* * *}$ & $-0.06(0.17)$ & $-0.65(0.32) *$ \\
\hline 2007 & - & $0.82(0.13)^{* * *}$ & $1.29(0.29)^{* * *}$ & $0.14(0.15)$ & $-0.25(0.21)$ \\
\hline 2005 & - & $0.55(0.11)^{* * *}$ & $0.81(0.26)^{* *}$ & $-0.02(0.12)$ & $-0.27(0.16)$ \\
\hline 2003 & - & $0.37(0.10)^{* *}$ & $0.77(0.23) * *$ & $0.13(0.10)$ & $-0.01(0.12)$ \\
\hline Population size (ln) & 4.6- & $1.68(0.12)^{* * *}$ & $2.40(0.22)^{* * *}$ & & \\
\hline \multicolumn{6}{|l|}{ Care needs of older } \\
\hline People aged 65 years & $6.7-$ & $-0.01(0.01)$ & $0.05(0.03)$ & $-0.03(0.01)$ & $-0.03(0.03)$ \\
\hline People receiving & $0.3-$ & $-0.03(0.01) *$ & $-0.02(0.03)$ & $-0.06(0.02)^{* *}$ & $-0.04(0.03)$ \\
\hline People living in & $0-14.8$ & $0.11(0.04)^{*}$ & $0.24(0.05)^{* * *}$ & $-0.04(0.02)$ & $-0.03(0.04)$ \\
\hline People living alone & $27.5-$ & $0.04(0.01)^{* *}$ & $0.05(0.02)^{*}$ & $0.02(0.01)^{*}$ & $-0.02(0.02)$ \\
\hline Pensioner's care & $0-108$ & $0.01(0.00)^{* *}$ & $0.05(0.01)^{* * *}$ & $-0.00(0.00)$ & $0.02(0.01)^{*}$ \\
\hline \multicolumn{6}{|l|}{ Economic situation } \\
\hline Tax revenue & $13.6-$ & $0.08(0.01) * * *$ & $0.03(0.03)$ & & $-0.02(0.03)$ \\
\hline Health and social care & $1.8-$ & $0.03(0.01)^{* * *}$ & $-0.04(0.02)$ & $0.01(0.01)$ & $0.06(0.02)^{* *}$ \\
\hline Central grants & $0-53.7$ & $-0.01(0.01)$ & $-0.05(0.03)$ & $-0.02(0.01)^{*}$ & $-0.02(0.02)$ \\
\hline Annual contribution & $-13.1-$ & $0.00(0.12)$ & $-0.03(0.04)$ & $0.21(0.13)$ & $0.03(0.03)$ \\
\hline \multicolumn{6}{|l|}{ Political ideology } \\
\hline Percentage of right- & $0-100$ & $0.00(0.00)$ & $0.01(0.01)$ & $0.00(0.00)$ & $0.00(0.00)$ \\
\hline
\end{tabular}

Note: ${ }^{*} p<.05 . * * p<.01 . * * * p<.001 ; \beta=$ regression coefficient; $S E=$ standard error; $\dagger$ Reference category $=$ municipality not using outsourcing.

Crude Model $=$ unadjusted model; Full Model $=$ adjusted for all variables; $\$=$ number of pensioner's care allowance recipients in 1000 inhabitants 